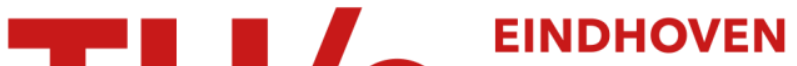 UNIVERSITY OF TECHNOLOGY
}

\section{The role of hydrogen during plasma beam deposition of amorphous thin films}

\section{Citation for published version (APA):}

Sanden, van de, M. C. M., Severens, R. J., Meulenbroeks, R. F. G., Graaf, de, M. J., Qing, Z., Otorbaev, D. K., Engeln, R. A. H., Gielen, J. W. A. M., Mullen, van der, J. J. A. M., \& Schram, D. C. (1995). The role of hydrogen during plasma beam deposition of amorphous thin films. Surface and Coatings Technology, 74-75(1-3), 1-9. https://doi.org/10.1016/0257-8972(95)08356-1

DOI:

10.1016/0257-8972(95)08356-1

Document status and date:

Published: 01/01/1995

\section{Document Version:}

Publisher's PDF, also known as Version of Record (includes final page, issue and volume numbers)

\section{Please check the document version of this publication:}

- A submitted manuscript is the version of the article upon submission and before peer-review. There can be important differences between the submitted version and the official published version of record. People interested in the research are advised to contact the author for the final version of the publication, or visit the $\mathrm{DOI}$ to the publisher's website.

- The final author version and the galley proof are versions of the publication after peer review.

- The final published version features the final layout of the paper including the volume, issue and page numbers.

Link to publication

\section{General rights}

Copyright and moral rights for the publications made accessible in the public portal are retained by the authors and/or other copyright owners and it is a condition of accessing publications that users recognise and abide by the legal requirements associated with these rights.

- Users may download and print one copy of any publication from the public portal for the purpose of private study or research.

- You may not further distribute the material or use it for any profit-making activity or commercial gain

- You may freely distribute the URL identifying the publication in the public portal.

If the publication is distributed under the terms of Article 25fa of the Dutch Copyright Act, indicated by the "Taverne" license above, please follow below link for the End User Agreement:

www.tue.nl/taverne

Take down policy

If you believe that this document breaches copyright please contact us at:

openaccess@tue.nl

providing details and we will investigate your claim. 


\title{
The role of hydrogen during plasma beam deposition of amorphous thin films
}

\author{
M.C.M. van de Sanden, R.J. Severens, R.F.G. Meulenbroeks, M.J. de Graaf, Z. Qing, \\ D.K. Otorbaev, R. Engeln, J.W.A.M. Gielen, J.A.M. van der Mullen, D.C. Schram \\ Department of Physics, Eindhoven University of Technology, P.O. Box 513, $600 \mathrm{MB}$ Eindhoven, Netherlands
}

\begin{abstract}
The influence of wall-associated $\mathrm{H}_{2}$ molecules and other hydrogen-containing monomers on the degree of ionization in the expanding thermal plasma used for the fast plasma beam deposition of amorphous hydrogenated carbon (a-C: $\mathrm{H}$ ) and amorphous hydrogenated silicon $(\mathrm{a}-\mathrm{Si}: \mathrm{H})$ was determined. Deposition models are discussed with emphasis on the specific role of the ion during deposition. The connection between the role of atomic hydrogen and the degree of ionization in the plasma beam deposition of $\mathrm{a}-\mathrm{C}: \mathrm{H}$ and $\mathrm{a}-\mathrm{Si}: \mathrm{H}$ is addressed.
\end{abstract}

Keywords: Recirculation; Thin film deposition; Expanding thermal plasma; Wall effects

\section{Introduction}

This paper deals with the role of hydrogen during the plasma beam deposition of amorphous hydrogenated silicon $(\mathrm{a}-\mathrm{Si}: \mathrm{H})$ and amorphous hydrogenated carbon $(\mathrm{a}-\mathrm{C}: \mathrm{H})$ from hydrogen-containing monomers. The importance of hydrogen can be illustrated by the observation that the $\mathrm{H}$ content in the monomer used for the deposition of the materials mentioned is usually higher than the stoichiometry of the film grown. Therefore etching of the surplus hydrogen by means of atomic hydrogen or another reactive radical should be considered as an important effect contributing to the film growth mechanism. The specific role of the ions during deposition should also be addressed, since, as will be demonstrated, the abundance of hydrogen and hydrogen-containing monomers influences the ion concentration in the plasma and thus the ion flux reaching the growing layer. We highlight this interconnection between hydrogen and the degree of ionization for the plasma beam deposition of a-Si:H and a-C:H.

\section{Wall effects in hydrogen-containing plasmas}

The role of hydrogen during plasma deposition is an intriguing subject $[1,2]$. Apart from being the simplest possible molecule, hydrogen is the molecule with the smallest possible mass. An important consequence of the latter is that typical rate coefficients for kinetic processes involving heavy particles are larger than for comparable reactions with argon. Furthermore, the diffusion of hydrogen is fast, leading to a large influence of transport processes in hydrogen-containing plasmas. Another specific feature of atomic hydrogen is the large adsorption rate on metal surfaces. This eventually leads to an enhanced association of atomic hydrogen on these surfaces, i.e. an incoming $\mathrm{H}$ radical with a wall-adsorbed $\mathrm{H}$ atom $[3,4]$. As will be shown, these properties of hydrogen have several consequences on the plasma characteristics. A recent review paper by Otorbaev et al. [4] was devoted to this subject. Here we summarize the main results and emphasize the consequences during the deposition of a-C:H and a-Si:H from hydrogencontaining monomers.

From detailed studies on a thermal arc plasma in a low background pressure (Fig. 1), it is now well established that a small fraction of hydrogen molecules has a large influence on the degree of ionization of the plasma [5]. The results for the electron density $n_{\mathrm{e}}$ for a pure argon plasma, as measured downstream of the exit of the arc, show that three-particle recombination of the $\mathrm{Ar}^{+}$ions produced in the arc is small compared with the transport properties, i.e. the ion fluence emanating from the arc is more or less conserved downstream. (For the electron density (typically $n_{\mathrm{e}}=10^{19}-10^{21} \mathrm{~m}^{-3}$ ) and temperature (typically $T_{\mathrm{e}}=1000-6000 \mathrm{~K}$ ) in the argon expanding thermal 


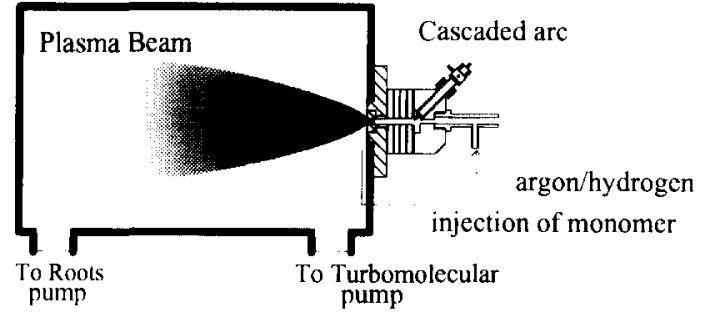

Fig. 1. The cascaded arc experiment. A thermal plasma at atmospheric pressure is created in a continuously operated d.c. arc, consisting of three cathodes, three to eight electrically isolated plates and an anode plate. All these parts are water cooled. The plasma expands into a low pressure region, creating a plasma beam. Usually the arc is operated in argon. Hydrogen is either admixed in the arc or injected in the beam. Monomers $\left(\mathrm{SiH}_{4}, \mathrm{CH}_{4}\right.$, etc.) are injected in the plasma beam.

plasma, the most important recombination process is three-particle recombination $\mathrm{e}+\mathrm{e}+\mathrm{Ar}^{+} \rightarrow \mathrm{e}+\mathrm{Ar}^{*}$. The recombination rate is given by $K_{\mathrm{rec}}=3.3 \times 10^{-21} T_{\mathrm{e}}^{9 / 2}$. It is easy to demonstrate that, at a plasma velocity of 2000 $\mathrm{m} \mathrm{s}^{-1}$, the loss by three-particle recombination can be neglected compared with the convective losses [6].) By comparing these results for $n_{\mathrm{e}}$ in a pure argon plasma with the results on a similar plasma with 2 vol. \% hydrogen of the total flow injected directly into the reactor vessel (Fig. 2(a)) [5], it is clear that the threeparticle recombination of the argon ions created in the arc cannot account for the enhanced recombination observed downstream. By admixing hydrogen in the arc instead of in the reactor vessel (Fig. 2), two effects can be distinguished. Firstly, the effect of hydrogen injection in the arc leads to a decrease in the ion fluence emanating from the arc. This can be observed in Fig. 2(b) for the smallest axial position as a decrease in the electron density as a function of the percentage of hydrogen. Furthermore, from Fig. 2, it can be determined that the other effect is caused by molecular hydrogen in the background, which is formed by wall association (or recombinative desorption) of atomic hydrogen produced in the arc with wall-adsorbed atomic hydrogen. The explanation of the efficient ion loss process, which is induced by molecular hydrogen, is given by the following sequence of reactions

$\mathrm{Ar}^{+}+\mathrm{H}_{2} \rightarrow \mathrm{ArH}^{+}+\mathrm{H}$

$\mathrm{ArH}^{+}+\mathrm{e} \rightarrow \mathrm{Ar}+\mathrm{H}^{*}$

Here the dissociative charge exchange reaction is the time- limiting step with a rate of approximately $10^{-15}$ $\mathrm{m}^{3} \mathrm{~s}^{-1}$ [5]. It should be noted that even small amounts of hydrogen lead to a strong decrease in the degree of ionization. For example, for an expanding plasma with $n_{\mathrm{e}}=10^{19} \mathrm{~m}^{-3}$ and $T_{\mathrm{e}}=2000 \mathrm{~K}$, the ion loss by means of three-particle recombination per argon ion is about 500 $\mathrm{s}^{-1}[6]$. For a hydrogen molecular density of $10^{18} \mathrm{~m}^{-3}$, the ion loss per argon ion by means of the reaction
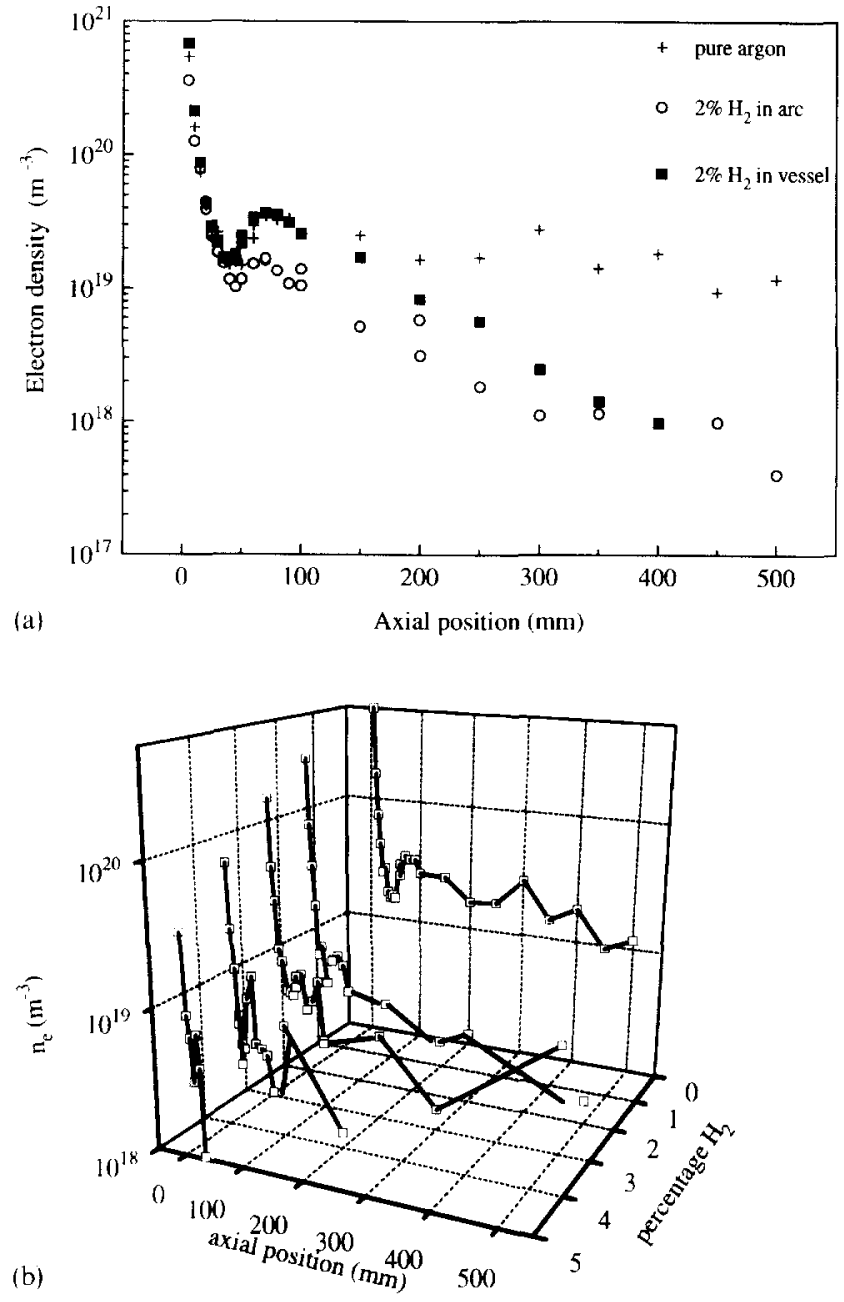

Fig. 2. (a) Measured electron density $n_{\mathrm{e}}$ on the axis for pure argon, $2 \% \mathrm{H}_{2}$ admixed in the arc and $2 \% \mathrm{H}_{2}$ admixed in the vessel. This clearly demonstrates that recirculating hydrogen is responsible for the decrease after $z=100 \mathrm{~mm}$. It should be noted that the electron density in the supersonic expansion is almost identical for all situations [5]. (b) Electron density $n_{\mathrm{e}}$ on the axis of the expanding thermal arc for different percentages of hydrogen admixed in the arc (pure argon, $2 \%, 3 \%, 4 \%$ and $5 \% \mathrm{H}_{2}$ ) as measured using Thomson scattering [5]. Axial position $0 \mathrm{~mm}$ corresponds to the onset of the expansion out of the thermal plasma (see Fig. 1). Even small amounts of hydrogen lower the measured $n_{\mathrm{e}}$ value significantly for axial positions larger than $40 \mathrm{~mm}$.

chain $(1)-(2)$ is a factor of two larger. The excited $\mathrm{H}$ atom in reaction (2) is in the $n=2$ state for a hydrogen molecule in the ground state. A higher excitation of the $\mathrm{H}$ atom $(n>2)$ requires a rovibrational excited $\mathrm{H}_{2}{ }^{v}, J$ molecule in the dissociative charge exchange step (Eq. (1)). It was demonstrated by Meulenbroeks et al. [5] that the reaction mechanism given in Eqs. (1)-(2) is in good agreement with the ion loss observed in Fig. 2. In the case of a pure hydrogen plasma, similar features were seen, i.e. an enhanced recombination of the ions produced in the arc [7]. As the dissociative charge exchange reaction (Eq. (1)) with a hydrogen ion is endothermic for $v<4$ (equivalent internal energy $E_{\mathrm{v}} \approx 1.8 \mathrm{eV}$ ), 
a significant rovibrational excitation of the hydrogen molecule in a pure hydrogen plasma is necessary. Possible mechanisms for the rovibrational excitation of the molecule include direct rovibrational excitation in the arc and subsequent freezing-in during the expansion [7] or rovibrational heating in the downstream plasma where temperatures are still around 2000-3000 K. Another mechanism of rovibrational excitation of the $\mathrm{H}_{2}$ molecule is recombinative desorption of $\mathrm{H}$ adsorbed on the wall induced by $\mathrm{H}$ atom radicals from the gas phase. The recombination energy of $4.5 \mathrm{eV}$ is approximately equally shared by the wall and the desorbing $\mathrm{H}_{2}$ molecule which leads to vibrational quantum states with $v \geqslant 4[3,8,9]$. Fractions of rovibrational excited molecules with $v \geqslant 4$ of smaller than $0.1 \%$ of the total molecular hydrogen density are necessary to explain the observed decrease in the ion density in a pure hydrogen plasma.

When using the plasma beam source shown in Fig. 1 for plasma deposition, hydrogen-containing monomers are injected downstream in the plasma beam. In this case, the arc is operated in argon and argon ions emanate from the arc. Because the electron temperature in the expanding plasma beam is low (less than $0.3 \mathrm{eV}$ ), the injected molecules are dissociated by charge exchange with the argon ion and a subsequent dissociative recombination of the molecular ion formed. For example, $\mathrm{SiH}_{4}$ is probably dissociated by means of the following sequence

$\mathrm{Ar}^{+}+\mathrm{SiH}_{4} \rightarrow \mathrm{SiH}_{3}^{+}+\mathrm{H}+\mathrm{Ar}$

$\mathrm{SiH}_{3}^{+}+\mathrm{e} \rightarrow \mathrm{SiH}_{2}+\mathrm{H}$

$\mathrm{Ar}^{+}+\mathrm{SiH}_{2} \rightarrow \mathrm{SiH}^{+}+\mathrm{H}+\mathrm{Ar}$, etc.

As can be concluded from reactions (3) and (4), the injection of the monomer used for deposition leads to a decrease in the degree of ionization. This decrease is, however, beneficial as the dissociated products have sticking probabilities which exceed the sticking probability of the feed gas. An unwanted effect is the recombinative desorption on the wall of the atomic hydrogen produced by the reaction chain (Eqs. (3)-(4)). These wall- associated hydrogen molecules enter the plasma beam again and lower the dissociation capability of the argon ions (see Eqs. (1) and (2)).

The effect of the injection of monomers on the plasma beam characteristics was clearly demonstrated by Meeusen et al. [10] and Dinescu et al. [11] for $\mathrm{Ar}-\mathrm{SiH}_{4}$ mixtures (see Fig. 3) used for a-Si: $\mathrm{H}$ deposition. In the former study, a decrease in the degree of ionization was clearly observed, caused both by the injected $\mathrm{SiH}_{4}$ molecules and the wall- associated $\mathrm{H}_{2}$ molecules. In the emission spectroscopy experiments by Dinescu et al. [11] on the hydrogen Balmer series in an $\mathrm{Ar}-\mathrm{SiH}_{4}$ mixture, another aspect of wall-associated hydrogen molecules was observed. A clear Balmer

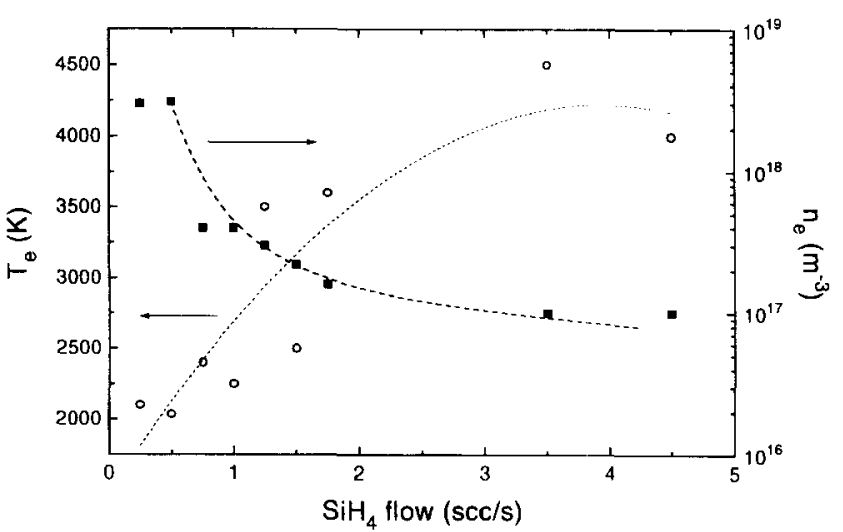

Fig. 3. Measured $n_{\mathrm{c}}$ and $T_{\mathrm{c}}$ values downstream of the exit of the arc at a distance of $32 \mathrm{~cm}$ as measured using a Langmuir double probe for different $\mathrm{SiH}_{4}$ flows. Other conditions: $I_{\text {arc }}=55 \mathrm{~A} ; p=20 \mathrm{~Pa} ; \mathrm{Ar}$ flow $=55 \mathrm{scc} \mathrm{s}^{-1}$.

spectrum was found with a relatively large intensity [11]. Since the electron temperature is low in the expanding beam, direct excitation of atomic $\mathrm{H}$ by means of electron impact can be neglected. Also excitation of atomic hydrogen during the dissociation of $\mathrm{SiH}_{4}$ by means of charge exchange with an argon ion (Eqs. (3) (5)) can be excluded by energy arguments. Therefore the excitation of the Balmer series of hydrogen, observed by Dinescu et al. [11], can only take place by dissociative recombination of rovibrationally excited $\mathrm{ArH}^{+, v, J}$ formed through charge exchange with a rovibrationally excited $\mathrm{H}_{2}^{v, J}$ molecule (see Eqs. (1) and (2)). The rovibrationally excited $\mathrm{H}_{2}^{v, J}$ molecules are formed by similar mechanisms to those described for the pure hydrogen plasma situation. Only a small amount of rovibrationally excited molecules (around $10^{15}-10^{16} \mathrm{~m}^{-3}$ with $v \geqslant 1$ ) is necessary to explain the observed emission of the Balmer lines by Dinescu et al. [11]. It should be noted that this excitation mechanism of the hydrogen Balmer series leads to an additional dissociation of the recirculating $\mathrm{H}_{2}$ molecules. The atomic hydrogen formed in this way, together with the atomic hydrogen formed in the dissociation of $\mathrm{SiH}_{4}$, can have a beneficial effect on the growth surface, since hydrogen can etch adsorbed species or passivate dangling bonds and, in this way, can determine the hydrogen content in the deposited a-Si:H $[1,2,12-14]$. In this respect, it is important to mention that it has been determined that the abstraction of atomic hydrogen from a crystalline silicon surface by atomic hydrogen is largely insensitive to the surface structure [12]. Similar effects to those described for $\mathrm{Ar}-\mathrm{SiH}_{4}$ were observed by Beulens et al. [15] for $\mathrm{Ar}-\mathrm{CH}_{4}$ mixtures used for a-C: $\mathrm{H}$ deposition.

As has been demonstrated, the presence of hydrogen molecules is essential for understanding the plasma beam source. The hydrogen molecules in the downstream plasma are formed in part at the wall of the reactor vessel by recombinative desorption. Since, for this to 
occur, atomic hydrogen needs to be transported from the plasma beam to the wall, flow patterns are important. At a given flow of approximately $50-100$ standard cubic centimetres $(\mathrm{scc}) \mathrm{s}^{-1}$ and a given pumping speed of 2000 $\mathrm{m}^{3} \mathrm{~h}^{-1}$, residence times are of the order of $0.1-1 \mathrm{~s}$. Since the transit times are in the $10^{-3} \mathrm{~s}$ range, many recirculations of the particles present take place before they leave the reactor vessel. The plasma interaction with the wall is therefore essential and the re-entering molecules formed at the wall contribute a significant fraction of the injected monomers as can be concluded from Fig. 2. Moreover, the degree of dissociation of $\mathrm{H}_{2}$ in the recirculating flow depends on the recombinative desorption coefficient $\gamma$ and the average amount of recirculations a particle undergoes before it is pumped away. Typical values for the latter are about 100 recirculations, while $\gamma \approx 0.05$ for stainless steel [16]. Furthermore, this means that, if we assume that every recirculating hydrogen atom reaches the wall once during every recirculation, almost all of the atomic hydrogen is converted into molecular hydrogen during the recirculation in the background gas. The low degree of dissociation measured by de Graaf [17] in a pure hydrogen plasma expanding into a low background pressure can be explained by the mixing of the highly dissociated beam of hydrogen into a background plasma with a low degree of dissociation. A similar analysis to that for $\mathrm{H}_{2}$ holds for other stable radicals, e.g. $\mathrm{SiH}_{3}$ which can form $\mathrm{SiH}_{4}$ or $\mathrm{Si}_{2} \mathrm{H}_{6}$ by association with wall-adsorbed $\mathrm{SiH}_{3}$ or $\mathrm{H}$.

An important question is to what extent are the described phenomena, which are essential in the description of the expanding plasma beam, of importance for totally different plasmas such as electron cyclotron resonance (ECR), r.f. plasma- enhanced chemical vapour deposition (RF-PECVD), microwave discharges etc? Several experiments and models have determined these effects, and it has been shown that during the RF-PECVD of a-C:H and a-Si:H the plasma-wall interaction is essential in the description of the radical content for $\mathrm{CH}_{3}$ and $\mathrm{SiH}_{3}[18,19]$. Thomas et al. [20] observed that both the electron temperature and electron density in a microwave-generated $\mathrm{Ar}-\mathrm{CH}_{4}$ plasma jet decreased due to the injection of $\mathrm{CH}_{4}$ in a pure argon plasma. Mucha et al. [21] and St.-Onge and Moisan [22] showed the importance of wall processes in the degree of dissociation of a microwave hydrogen plasma by changing the wall temperature. This directly affects the recombinative desorption coefficient $\gamma$ of hydrogen on silica which is activated by approximately $0.1 \mathrm{eV}$. Stoffels et al. [23] needed the specific influence of the wall to explain the negative ion density measured in a hydrogen r.f. capacitively coupled plasma. Also, in the case of negative ion source modelling by Berlemont et al. [24], the wall association of $\mathrm{H}$ plays an important role as the atomic hydrogen fraction is important in the quenching of the negative $\mathrm{H}^{-}$ion [4]. The influence of copper surfaces on negative ion sources, which are known to be very efficient in the generation of rovibrationally excited $\mathrm{H}_{2}{ }^{0}, J$ molecules needed for negative ion production [3,4], has not been addressed in detail, although indications of an enhanced $\mathrm{H}^{-}$production have been described by Al-Jabouri [25].

Clearly plasma-wall interactions in combination with flow patterns are general observed phenomena in all types of plasma containing hydrogen. As dissociative charge exchange with molecules is more important for higher electron density plasmas, excitation of the hydrogen atoms formed by means of dissociative recombination of the $\mathrm{ArH}^{+}$ion also becomes significant. Therefore, for the expanding thermal plasma (with low $T_{\mathrm{e}}$ and high $n_{\mathrm{e}}$ ) $[5,6]$ and for microwave discharges with electron densities of up to $10^{18} \mathrm{~m}^{-3}$ and electron temperatures in the region of $2 \mathrm{eV}$, the Balmer line excitation by dissociative recombination should be taken into account $[22,26]$. As demonstrated by Meulenbroeks et al. [5] and Dinescu et al. [11], only small fractions of rovibrationally excited hydrogen molecules are necessary to excite the hydrogen Balmer series of atomic $\mathrm{H}$. Therefore, in general, performing actinometry on atomic hydrogen to determine the ground state density in these high density sources $\left(n_{\mathrm{e}}>10^{17} \mathrm{~m}^{-3}\right)$ should be performed with great care.

\section{Deposition of thin films}

Many papers have been devoted to the specific role of hydrogen during the deposition of a-C: $\mathrm{H}$ and a-Si: $\mathrm{H}$ from $\mathrm{CH}_{4^{-}}$or $\mathrm{C}_{2} \mathrm{H}_{2^{-}}$and $\mathrm{SiH}_{4}$-containing plasmas [27-30]. The passivation of the dangling bonds and the creation of growth sites by hydrogen abstraction reactions on the growth surface are important in both the deposition of a-Si:H and a-C:H. Another aspect is the (preferential) etching of the surplus hydrogen to obtain the desired stoichiometry or $\mathrm{sp}^{3}$ to $\mathrm{sp}^{2}$ ratio (in the case of carbon deposition).

The purpose of this paper is not to repeat all the results in the literature but to concentrate on the possible connection between the role of the etching agent atomic hydrogen and the influence of the ions on the deposition mechanism. As shown in the preceding section, this connection is evident in the plasma beam deposition of thin films. The deposition of $\mathrm{a}-\mathrm{C}: \mathrm{H}$ is described first followed by the deposition of a-Si: $\mathrm{H}$.

\subsection{Fast deposition of $a-C: H$}

Several experiments have indicated that growing hard, dense a-C: $\mathrm{H}$ requires a certain ion kinetic energy $[2,27,28]$. The nature of the dominant precursor for the growth of good quality a-C: $\mathrm{H}$ is still uncertain, but a preference is for the low sticking probability $\mathrm{CH}_{3}$ radical 
$[18,27]$. As the sticking probability is low, the radicals can find a good adsorption site to cross-link and good quality material is grown [18]. Models have been developed based on the knowledge gained from ion beam experiments and computer simulations of the ion kinetics. Models by Robertson [27], Lifshitz et al. [28], Fourches and Turban [29], Rhallabi and Catherine [30] and Möller [18,31] for a-C:H and amorphous carbon $(\mathrm{a}-\mathrm{C})$ have shown good correspondence between measurements and experiments. In all these models, the ion and, more specifically, the ion energy plays a crucial role. To obtain a high $\mathrm{sp}^{3}$ content, graphitic sites must be avoided, which is thought to be governed by the ion kinetic energy $[18,27,28,31-33]$. Therefore $\mathrm{a}-\mathrm{C}: \mathrm{H}$ is deposited on the powered r.f. electrode or, in the case of a downstream plasma, an additional bias is applied, which in both cases leads to large d.c. biases and accordingly high ion energies (greater than $100 \mathrm{eV}$ ). Others have used ion beam techniques, such as the filtered ion beam deposition of a-C: $\mathrm{H}$, where ion energies as large as $500 \mathrm{eV}$ are employed [34]. A recently developed technique is the use of a laser to ablate a carbon target. Unhydrogenated carbon layers are produced with a high sp ${ }^{3}$ content [35]. The high sp ${ }^{3}$ content is obtained by high energy ions (approximately $1 \mathrm{keV}$ ) which are accelerated in the laser plasma produced by the laser interaction with the carbon target [36]. For RF-PECVD of a-C: H, Fourches and Turban [29] have demonstrated that the growth rate is well described by the growth from an adsorbed layer. This adsorbed layer is a region which consists of physisorbed and chemisorbed growth precursors. In this case, Fourches and Turban [29] found that the growth rate scales with the ion energy flux rather than with the ion kinetic energy. However, they did not include the specific role of atomic hydrogen, i.e. they did not include etching by means of atomic hydrogen or other radicals, e.g. $\mathrm{CH}_{3}$. The group of Möller has demonstrated that high ion energy is not essential for the deposition of a-C:H from an ECR plasma where the ion kinetic energy is as low as $30 \mathrm{eV}$ $[18,31,32]$. Here it should be noted that the potential energy of the ion is not considered in the analysis. In this respect, the heat flux experiments of Kersten et al. [37] should be mentioned, which demonstrate that an important component in the heat flux towards the substrate is the recombination of the dominant ion on the substrate. Therefore an interesting question is whether the ion energy flux or, more generally, the energy flux towards the growth surface determines the growth kinetics or whether a specific ion kinetic energy is necessary to promote or prevent a certain growth mechanism. A model based on the deposition from an adsorbed layer, developed by Möller [18,31] for the deposition of a-C: $\mathrm{H}$, includes the specific role of the ion ("ion stitching") and the etching role of atomic hydrogen. Good agreement between the experiments and model are obtained for the growth rate, $\mathrm{sp}^{2} / \mathrm{sp}^{3}$ ratio and the hydrogen content in the layer. The dependence on the ion kinetic energy is not explicit in the model of Möller $[18,31]$, in contrast with that of Fourches and Turban [29]. On the other hand, certain kinetic coefficients used in the modelling of the growth of the deposition of a-C: $\mathrm{H}$ depend critically on the ion kinetic energy $[18,31]$.

As can be concluded from the results discussed, the ion plays a more or less dominant role in the description of the growth mechanism of a-C:H. Many methods indicate that a relatively large ion kinetic energy in the range $50-150 \mathrm{eV}$ is necessary to grow hard, dense layers, although the results of Möller and coworkers [32] indicate otherwise. Another indication that high ion energy is not a prerequisite for dense, hard material is given by the fast plasma beam deposition of a-C:H from an $\mathrm{Ar}-\mathrm{CH}_{4}$ plasma using an expanding thermal arc (typical growth rate is $10-100 \mathrm{~nm} \mathrm{~s}^{-1}$ ) $[38,39]$. In this case the self-bias is low, typically $-1.5 \mathrm{~V}$, so that the ion energy is low. However, high refractive index material is grown (see Fig. 4), indicating dense, hard material $[15,38,39]$. In Fig. 4, the layer properties, such as hardness, refractive index, band gap and $\mathrm{C} / \mathrm{H}$ ratio, are given as a function of the energy factor $Q$. This energy factor $Q$ is a function of the arc parameters alone and is defined by

$Q=\frac{\mathrm{C}_{\text {flow }}}{P_{\text {arc }} \mathrm{Ar}_{\text {flow }}}$

where $\mathrm{C}_{\text {flow }}$ is the amount of carbon atom flow, $P_{\text {arc }}$ is the power of the arc and $\mathrm{Ar}_{\text {flow }}$ is the amount of argon flow. The amount of ions emanating from the arc is proportional to both $P_{\text {arc }}$ and $\operatorname{Ar}_{\text {flow }}$. Therefore $Q$ is proportional to the amount of ions available per dissociated carbon atom and thus, indirectly, the amount of energy per deposited carbon particle. For hard layers of a-C: $\mathrm{H}$, the latter amounts to approximately $50 \mathrm{eV}$ per deposited carbon particle at a growth rate of $50-100 \mathrm{~nm} \mathrm{~s}^{-1}$ [15]. As the ion density is one to two orders of magnitude larger during the deposition of a-C $: \mathrm{H}$ using the expanding thermal arc compared with

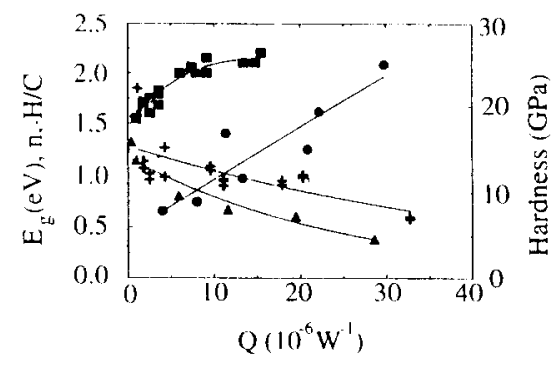

Fig. 4. Refractive index $n(\boldsymbol{\square})$, band gap $E_{\mathrm{g}}(+), \mathrm{H} / \mathrm{C}$ ratio $(\boldsymbol{\Delta})$ and hardness (O) for plasma-deposited a-C:H vs. the energy factor which is a function of the arc parameters alone (see Ref. [15] and text for further details). 
RF-PECVD, the ion energy flux is comparable. This is in agreement with the observations of Fourches and Turban [29] who found a scaling with ion energy flux rather than with the ion kinetic energy. This discussion excludes the possible beneficial effect of ions penetrating the growing layer, resulting in a densification effect of the bulk material [27]. Also the contribution of radicals, impinging on the growing layer and transferring energy (by means of etching), is not considered in the present models, although it could play an important role during diamond and graphite deposition from carboncontaining material.

Further support for the indication that ions with relatively large kinetic energies are not essential in obtaining high $\mathrm{sp}^{3}$ or $\mathrm{sp}^{2}$ content is illustrated by considering the deposition of diamond and graphite using the expanding plasma beam. An example of diamond deposition using the expanding plasma beam setup is given in Fig. 5, where Raman spectra of diamond depositions are given as a function of the vessel pressure. The condition under which diamond deposition usually occurs involves a high dilution of the carbon-containing monomer in molecular hydrogen. As can be seen, during plasma beam deposition, an increase in the vessel pressure leads to diamond formation [15,40], as shown by the appearance of the characteristic diamond peak at $1333 \mathrm{~cm}^{-1}$. This dependence on the vessel pressure is attributed to the preferential etching of graphitic sites by atomic hydrogen and the stabilizing character of atomic hydrogen in passivating the dangling bonds on the growth surface $[2,27,41]$. From ion density measure-

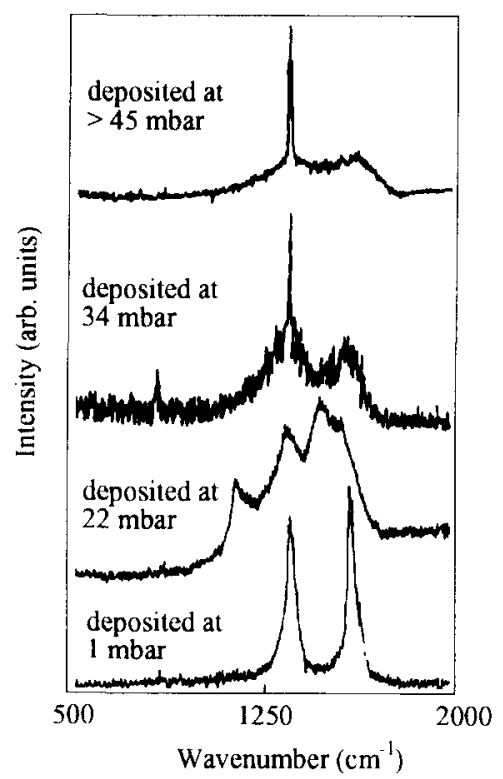

Fig. 5. Raman spectra of deposits obtained under the following conditions: Ar flow $=20 \mathrm{scc} \mathrm{s}^{-1} ; \mathrm{H}_{2}$ flow $=20 \mathrm{scc} \mathrm{s}^{-1} ; \mathrm{CH}_{4}$ flow $=0.2$ $\operatorname{scc~s}^{-1} ; I_{\text {arc }}=35 \mathrm{~A} ; T_{\text {substrate }}=1000^{\circ} \mathrm{C}$; different reactor pressures. For the highest pressure, the diamond peak at $1333 \mathrm{~cm}^{-1}$ is clearly visible (see Ref. [40] for further details). ments under similar conditions, it is clear that the ions do not play a role in the plasma beam deposition of diamond from $\mathrm{Ar}-\mathrm{H}_{2}-\mathrm{CH}_{4}$ plasmas. Similar conclusions can be drawn from Fig. 6 [42], where the Raman spectra for graphite (single-crystal graphite peak at $1581 \mathrm{~cm}^{-1}$, defective graphite peak at about $1355 \mathrm{~cm}^{-1}$ and shoulder peak at $1621 \mathrm{~cm}^{-1}$ originating from edge effects of finite micro-crystals) are shown as a function of the amount of hydrogen admixed with the $\mathrm{Ar}-\mathrm{C}_{2} \mathrm{H}_{2}$ plasma during plasma beam deposition of graphite. As can be seen, the best graphite is grown (the largest single-crystal peak) at the highest hydrogen content, which has the lowest degree of ionization. The growth rate decreases which may indicate a connection between the dissociative capacity of the ions (see Eqs. (1) and (2)) and the surface activity of the growth precursor during deposition. It should be noted that, in both cases, i.e. diamond and graphite deposition, the substrate temperatures are high in comparison with the temperature during a-C:H deposition $\left(800{ }^{\circ} \mathrm{C}\right.$ and $1000{ }^{\circ} \mathrm{C}$ respectively compared with $20-200{ }^{\circ} \mathrm{C}$ in the case of a-C: $\mathrm{H}$ deposition). These diamond results confirm that there are other mechanisms

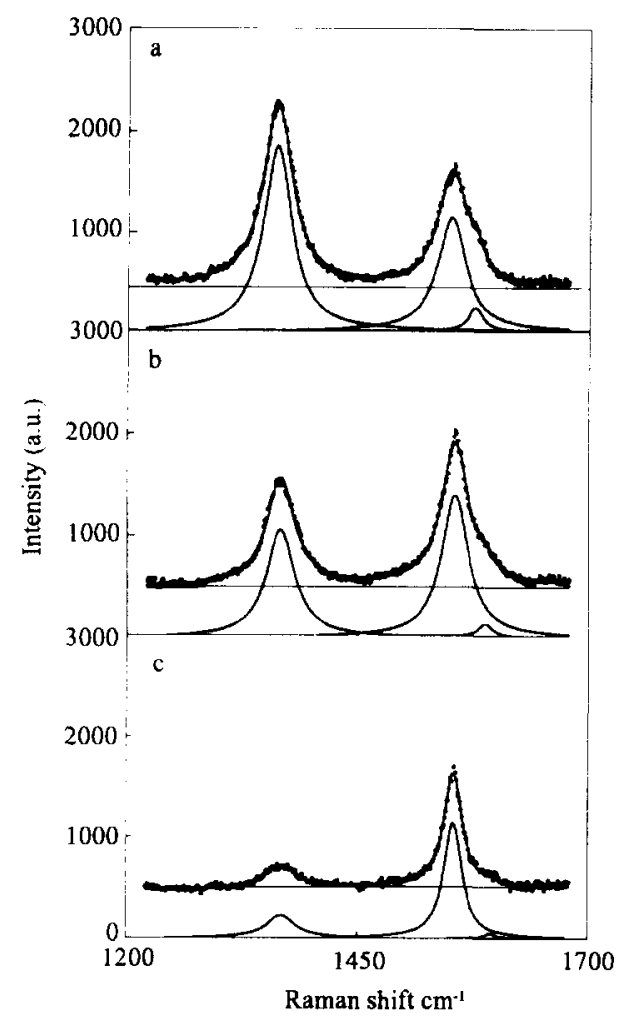

Fig. 6. Effect of increasing $\mathrm{H}_{2}$ admixture on the Raman spectrum with other reactor settings constant: Ar flow $=100 \mathrm{scc} \mathrm{s}^{-1} ; \mathrm{C}_{2} \mathrm{H}_{2}$ flow $=1 \mathrm{scc} \mathrm{s}^{-1} ; I_{\mathrm{arc}}=50 \mathrm{~A} ; p=100 \mathrm{~Pa} . \mathrm{H}_{2}$ admixture in arc: 5 (top), 10 (middle) and 20 (bottom) $\mathrm{scc} \mathrm{s}^{-1} ; T_{\text {substrate }}=840^{\circ} \mathrm{C}$. The bottom Raman spectrum corresponds to good quality graphite. Peak identification: single-crystal graphite peak at $1581 \mathrm{~cm}^{-1}$; defective graphite peak at about $1355 \mathrm{~cm}^{-1}$; shoulder peak at $1621 \mathrm{~cm}^{-1}$ originating from edge effects of finite micro-crystals (see Ref. [42] for further details). 
which lead to diamond deposition, namely a high substrate temperature in combination with atomic hydrogen adsorption and abstraction reaction kinetics. Therefore the surface chemistry may not be fully dominated by ion kinetics for the substrate temperature of a-C:H deposition. From the diamond and graphite deposition in general and from the plasma beam deposition of $\mathrm{a}-\mathrm{C}: \mathrm{H}$ in particular, it can be concluded that $\mathrm{H}$ chemistry may also be important.

\subsection{Fast deposition of a-Si:H}

An important material parameter of $\mathrm{a}-\mathrm{Si}: \mathrm{H}$ is the hydrogen content. As has been shown by many investigators, the main parameters, such as the refractive index, mass density and dangling bond density, scale with the hydrogen content. More importantly, the hydrogen content has been shown to be connected with the metastability of a-Si:H material in the sense that the hydrogen concentration probably plays a crucial role in the Staebler-Wronski effect [1]. Typically, the hydrogen percentage for good quality RF-PECVD a-Si:H is around $10 \%$. During the deposition of a-Si: $\mathrm{H}$, many process parameters determine the hydrogen content, e.g. the substrate temperature, hydrogen dilution, plasma power, etc. On a microscopic level, this means that the etching of hydrogen and surface-adsorbed radicals by atomic hydrogen, cross-linking and subsequent effusion out of the bulk occur during growth. Different deposition mechanisms for good quality a-Si: $\mathrm{H}$ have been proposed $[13,43-47]$ based on different precursors. The mechanism which claims that the $\mathrm{SiH}_{3}$ radical is the precursor for a-Si : H growth seems to be favoured [13], although there is still some debate. This model is purely a radical model in the sense that the ions present during RF-PECVD do not play a role. What is needed is the surface mobility of the low sticking probability $\mathrm{SiH}_{3}$ radical. Furthermore, its relatively long lifetime in the $\mathrm{SiH}_{4}$ plasma leads to a larger probability that this radical reaches the growth surface. On the other hand, the presence of ions can provide a type of ion- enhanced surface mobility, a concept necessary in the deposition model based on the indirect deposition of the $\mathrm{SiH}_{2}$ radical through the production of $\mathrm{Si}_{2} \mathrm{H}_{6}$ in the gas phase. Recent results using VHF PECVD of a-Si:H [48-52] lead to conflicting conclusions on the deposition mechanism. Some results indicate a larger role of the ions and even demonstrate a dependence of the growth on the ion density [49,51]; others indicate a larger dissociation degree of silane $[50,52]$. On the other hand, deposition of good quality a-Si:H by means of an expanding thermal $\mathrm{Ar}-\mathrm{H}_{2}-\mathrm{SiH}_{4}$ plasma clearly shows that ions do not play a role during deposition. This is shown by Fig. 7 where the growth rate of a-Si: $\mathrm{H}$ and the ion flux measured just in front of the substrate are given as a function of the admixed $\mathrm{H}_{2}$. As can be seen, the growth
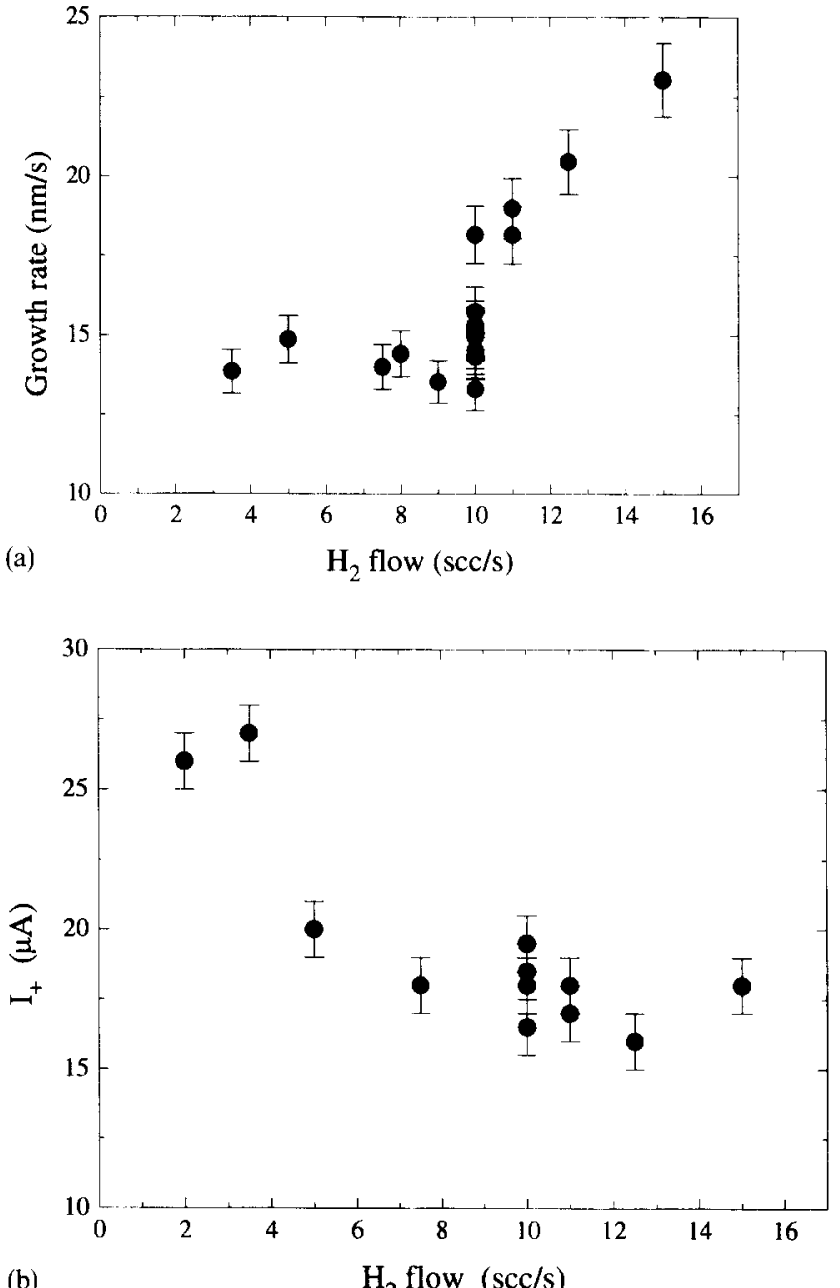

Fig. 7. (a) Growth rate of plasma-beam-deposited a-Si:H vs. the $\mathrm{H}_{2}$ admixed in the arc as determined by in situ ellipsometry. (b) Ion saturation current as measured using a Langmuir probe positioned in front of the substrate holder for identical conditions as in (a).

rate increases whereas the ion flux decreases [53,54]. Here the connection between hydrogen and the ions emanating from the arc is again important. As the hydrogen is admixed in the arc and $\mathrm{SiH}_{4}$ is injected in the supersonic expansion, the ion density relative to the hydrogen atomic density is relatively low (see Fig. 2(b)). Therefore the charge exchange route as described in an early paper by Meeusen et al. [10]

$\mathrm{H}^{+}+\mathrm{SiH}_{4} \rightarrow \mathrm{SiH}_{3}^{+}+\mathrm{H}_{2}$

$\mathrm{SiH}_{3}^{+}+\mathrm{e} \rightarrow \mathrm{SiH}_{2}+\mathrm{H}$

leading dominantly to the $\mathrm{SiH}_{2}$ radical is replaced by a hydrogen abstraction route [54]

$\mathrm{H}+\mathrm{SiH}_{4} \rightarrow \mathrm{SiH}_{3}+\mathrm{H}_{2}$

which leads to the $\mathrm{SiH}_{3}$ radical. Of course, depending on the specific conditions, other radicals are formed by subsequent reactions with atomic and molecular hydrogen and other silane fragments in the gas phase. 
It is clear that the atomic hydrogen fraction in this case is responsible for the creation of the radicals (as opposed to the electron-induced kinetics of RF-PECVD or the dissociative charge exchange route of reactions (7) and (8)) and also for the final etching of the growing layer. As the atomic hydrogen can be created through a reaction sequence described by Eqs. (1) and (2), this clearly shows the interconnection between the atomic hydrogen present in the plasma and the ion density. Preliminary results on replacing $\mathrm{H}_{2}$ by $\mathrm{D}_{2}$ and IR analysis of the deposited layers indicate that practically all hydrogen in the plasma-beam-deposited a-Si:H originates from $\mathrm{SiH}_{4}$.

\section{Conclusions}

The role of hydrogen during plasma deposition has been reviewed. As has been demonstrated, even small fractions of hydrogen molecules lead to a significant decrease in the degree of ionization. On the other hand, ions may be important in the dissociation of molecular hydrogen in plasmas. Wall processes play a role as they support the association of atomic hydrogen. Hydrogencontaining monomers have similar effects during the deposition of materials such as a-Si:H and a-C:H. The reason is that the residence time of the particles in a plasma is much larger than the typical transit times. Therefore many wall interactions take place in which the dissociation products associate again and re-enter the plasma. This shows the interaction between wall processes and plasma transport. Furthermore, it has been shown that the injected monomers form only part of the monomers present in the plasma.

An important difference between a-C: $\mathrm{H}$ and a-Si: $\mathrm{H}$ is the influence of the ions during growth. For the latter, it is believed that the ions play a minor role, whereas for a-C: $\mathrm{H}$ deposition, the present belief is that a high ion kinetic energy is necessary to increase the $\mathrm{sp}^{3}$ content and the mass density and hardness. The results on an expanding thermal plasma indicate an ion energy flux dependence since the specific ion kinetic energy is low. Therefore it is important to quantify to what extent the ions contribute to growth and what is the role of $\mathrm{H}$ chemistry.

\section{Acknowledgments}

This work was supported in part by the Foundation for Fundamental Research on Matter (FOM), the Netherlands Technology Foundation (STW), the Netherlands Organization for Energy and Environment (NOVEM) and the Royal Netherlands Academy of Arts and Sciences. The skilful technical assistance of M.J.F. van de Sanden, A.B.M. Hüsken and H.M. de Jong is gratefully acknowledged.

\section{References}

[1] W. Luft and Y. Simon Tsuo, Hydrogenated Amorphous Silicon Alloy Deposition Processes, Marcel Dekker, New York, 1993.

[2] R.E. Clausing, J.C. Angus, L.L. Horton and P. Koidl (eds.), Diamond and Diamond-like Films and Coatings, NATO ASI Series, Series B: Physics Vol. 266, Plenum, New York, 1991.

[3] B. Jackson and M. Persson, J. Chem. Phys., 96 (1992) 2378.

[4] D.K. Otorbaev, M.C.M. van de Sanden and D.C. Schram, submitted for publication.

[5] R.F.G. Meulenbroeks, A.J. van Beek, A.J.G. van Helvoort, M.C.M. van de Sanden and D.C. Schram, Phys. Rev. E, 49 \{1994) 4397.

[6] M.C.M. van de Sanden, J.M. de Regt and D.C. Schram, Phys. Rev. E, 47 (1993) 2792. M.C.M. van de Sanden, J.M. de Regt and D.C. Schram, Plasma Sources: Sci. Technol, in press. M.C.M. van de Sanden, R.J. van Bercken and D.C. Schram, Plasma Sources: Sci. Technol, in press.

[7] M.J. de Graaf, R.J. Severens, R.P. Dahiya, M.C.M. van de Sanden and D.C. Schram, Phys. Rev. E, 48 (1993) 2098.

[8] P.J. Eenhuistra, J.H.M. Bonnie, J. Los and H.J. Hopman, Phys. Rev. Lett., 60 (1988) 341.

[9] R.I. Hall, I. Cadez, M. Landau, F. Pichou and C. Schermann, Phys. Rev. Lett., 60 (1988) 337.

[10] G.J. Meeusen, E.A. Ershov-Pavlov, R.F.G. Meulenbroeks, M.C.M. van de Sanden and D.C. Schram, J. Appl. Phys., 71 (1992) 4156.

[11] G. Dinescu, R.J. Severens, G.B.J. Brussaard, M.C.M. van de Sanden and D.C. Schram, in M.C.M. van de Sanden (ed.), Proc. Eur. Sect. Conf. on the Atomic and Molecular Physics of Ionized Gases (ESCAMPIG XIJ), Netherlands, 1994, Vol. 18E, European Physical Society, 1994.

[12] S.F. Shane, K.W. Kolasinski and R.N. Zare, J. Chem. Phys., 97 (1992) 3704 .

[13] J.R. Abelson, Appl. Phys. A, 56 (1993) 493.

[14] Y. Muramatsu and N. Yabumoto, Appl. Phys. Lett., 49 (1986) 1230 .

[15] J.J. Beulens, A.J.M. Buuron and D.C. Schram, Surf. Coat. Technol., 47 (1991) 401.

[16] B.J. Wood and H. Wise, J. Chem. Phys., 66 (1962) 1049.

[17] M.J. de Graaf, Ph.D. Thesis, Eindhoven University of Technology, Netherlands, 1994.

[18] W. Möller, Appl. Phys. A, 56 (1993) 527.

[19] M.J. Kushner, J. Appl. Phys., 63 (1988) 2532.

[20] L. Thomas, J.L. Jeauberteau, J. Aubreton, A. Catherinot, A.R. Da Souza and M.J. Cinelli, Appl. Phys. Lett., 64 (1994) 2643.

[21] J.A. Mucha, D.L. Flamm and D.E. Ibbotson, J. Appl. Phys., 65 (1989) 3448.

[22] L. St.-Onge and M. Moisan, Plasma Chem. Plasma Proc., 14 (1994) 87.

[23] W.W. Stoffels, E. Stoffels, F.T.H. den Hartog, G.M.W. Kroesen and F.J. de Hoog, Acta Phys. Univ. Comenianae, 34 (1993) 69.

[24] P. Berlemont, D.A. Skinner and M. Bacal, Rev. Sci. Instrum., 64 (1993) 2721

[25] A.L. Al-Jabouri, personal communication, 1994.

[26] J. Laimer and S. Matsumoto, Plasma Chem. Plasma Proc., 14 (1994) 117.

[27] J. Robertson, Diamond Relat. Mater, 2 (1993) 984.

[28] Y. Lifshitz, S.R. Kasi and J.W. Rabalais, Phys. Rev. Lett., 62 (1989) 1290.

[29] N. Fourches and G. Turban, Thin Solid Films, 240 (1994) 28. 
[30] A. Rhallabi and Y. Catherine, IEEE Trans. Plasma Sci., 19 (1991) 270

[31] W. Möller, Appl. Phys. Lett., 59 (1991) 2391.

[32] A. von Keudell, W. Möller and R. Hytry, Appl. Phys. Lett., 62 (1993) 937. P. Reinke, W. Jacob and W. Möller, J. Appl. Phys., 74 (1993) 1354.

[33] D.R. McKenzie, D. Muller and B.A. Pailthorpe, Phys. Rev. Lett., 67 (1991) 773.

[34] P.J. Fallon, V.S. Veerasamy, C.A. Davis, J. Robertson, G.A.J. Amaratunga, W.I. Milne and J. Koskinen, Phys. Rev. B, 48 (1993) 4777.

[35] F. Davanloo, E.M. Juengerman, D.R. Jander, T.J. Lee and C.B. Collins, J. Appl. Phys., 67 (1990) 2081.

[36] J. Stevefelt and C.B. Collins, J. Phys. D, 24 (1991) 2149.

[37] H. Kersten, R.J.J.M. Snijkers, J. Schulze, G.M.W. Kroesen, H. Deutsch and F.J. de Hoog, Appl. Phys. Lett., 64 (1994) 1496.

[38] G.M.W. Kroesen, D.C. Schram and M.J.F. van de Sande, Plasma Chem. Plasma Proc., 10 (1990) 49.

[39] J.W.A.M. Gielen, M.C.M. van de Sanden and D.C. Schram, to be published.

[40] A.J.M. Buuron, J.J. Beulens, P. Groot, J. Bakker and D.C. Schram, Thin Solid Films, 212 (1992) 282.

[41] P. Joeris, C. Benndorf and S. Bohr, J. Appl. Phys., 71 (1992) 4638.

[42] A.J.M. Buuron, J.J. Beulens, M.J.F. van de Sande, D.C. Schram and J.G. van der Laan, Fusion Technol., 19 (1991) 2049.
[43] R. Robertson, D. Hills, H. Chatham and A. Gallagher, Appl. Phys. Lett., 43 (1983) 544. R. Robertson and A. Gallagher, J. Appl. Phys., 59 (1986) 3402.

[44] J. Perrin and T. Broekhuizen, Appl. Phys. Lett., 50 (1987) 433.

[45] A. Matsuda and K. Tanaka, J. Appl. Phys., 60 (1986) 2351.

[46] J.L. Guizot, K. Nomoto and A. Matsuda, Surf. Sci., 244 (1991) 22.

[47] S. Veprek and M.G.J. Veprek-Heijman, Appl. Phys. Lett., 56 (1990) 1766.

[48] J. Perrin, Y. Takeda, N. Hirano, H. Matsura and A. Matsuda, Jpn. J. Appl. Phys., 28 (1989) 5.

[49] M. Heintze, R. Zedlitz and G.H. Bauer, J. Phys. D, 26 (1993) 1781.

[50] G. Bruno, P. Capezutto and G. Cicala, Pure Appl. Chem., 64 (1992) 725 .

[51] W.G.J.H.M. van Sark, J. Bezemer and W.F. van de Weg, Surf. Coat. Technol., 74-75 (1995) 63.

[52] F. Finger, U. Kroll, V. Viret, A. Shah, W. Beyer, X.M. Chang, J. Weber, A. Howling and Ch. Hollenstein, J. Appl. Phys., 71 (1992) 5665.

[53] R.J. Severens, G.B.J. Brussaard, M.C.M. van de Sanden and D.C. Schram, in M.C.M. van de Sanden (ed.), Proc. Eur. Sect. Conf. on the Atomic and Molecular Physics of lonized Gases (ESCAMPIG XII), Netherlands, 1994, Vol. 18E, European Physical Society, 1994.

[54] R.J. Severens, G.B.J. Brussaard, M.C.M. van de Sanden and D.C. Schram, to be published. 